\title{
A Nociceptive Signaling Role for Neuromedin B
}

\author{
Santosh K. Mishra, Sarah Holzman, and Mark A. Hoon \\ Molecular Genetics Unit, Laboratory of Sensory Biology, National Institute of Dental and Craniofacial Health, National Institutes of Health, Bethesda MD \\ 20892
}

Here we used an array-based differential screen to uncover the expression of the neuropeptide neuromedin B (NMB) in the trigeminal ganglia of mice. Double-labeling experiments reveal NMB is expressed in a subset of sensory neurons that colabel with calcitonin gene-related peptide and TRPV1 suggestive of a role for NMB in nociception. Indeed, administration of NMB antagonist greatly attenuates edema and nerve sensitization following stimulation of peripheral nerves with mustard oil, demonstrating that NMB contributes to neurogenic inflammation. Moreover, direct injection of NMB causes local swelling and nociceptive sensitization. Interestingly, we also find that the receptor for NMB is expressed in interneurons in the superficial layers of the dorsal horn. We used NMB-saporin to specifically eliminate NMBR-expressing neurons and determined they are required in responses to noxious heat, but not for reaction to mechanical and pruritic stimuli. Thus, NMB may be a neurotransmitter that is selectively involved in the perception of thermal stimuli.

\section{Introduction}

Neuropeptides and their receptors are important in somatosensory signaling pathways. Many different peptides have been reported to be present in the trigeminal (TG) and dorsal root ganglia (DRG), including substance $\mathrm{P}(\mathrm{SP})$, calcitonin generelated peptide (CGRP), galanin, neuropeptide Y (NPY), and gastrin releasing peptide (GRP) (Zhang et al., 1995; Bergman et al., 1996; Sun and Chen, 2007; Xu et al., 2010). SP and CGRP are the best characterized of these neuropeptides and are involved in peripheral and central nociceptive processes. They enhance excitatory stimulation in the dorsal horn of the spinal cord and are also released in the periphery, resulting in the local heating, wheal, and flare, a reaction known as neurogenic inflammation (Brain and Cox, 2006).

Neuromedin B (NMB) and GRP are the only two members of the mammalian bombesin family of peptides. These two peptides activate structurally similar but pharmacologically distinct G-protein-coupled receptors: the NMB receptor (NMBR) and the GRP receptor (GRPR) (Corjay et al., 1991; Jensen et al., 2008). In the periphery NMB and GRP have a wide variety of actions including smooth muscle contraction and exocrine and endocrine functions (Heasley, 2001). In the CNS these peptides regulate food intake and body temperature, as well as stress behavioral responses (Battey and Wada, 1991; Ohki-Hamazaki et al., 1999;

\footnotetext{
Received March 28, 2012; revised April 30, 2012; accepted May 5, 2012.

Author contributions: S.K.M. and M.A.H. designed research;S.K.M., S.H., and M.A.H. performed research; S.K.M., S.H., and M.A.H. analyzed data; M.A.H. wrote the paper.

This research was supported by the intramural research program of the National Institutes of Health-National Institute of Dental and Craniofacial Health (M.A.H.) The mouse strain used for this research project, STOCK Tg(NmbrEGFP), was obtained from the Mutant Mouse Regional Resource (enter (MMRRC), a National Center for Research Resources- NIH-funded strain repository, and was donated to the MMRRC by the National Institute of Neurological Disorders and Stroke funded GENSAT BAC transgenic project. We are grateful to Nick Ryba for encouragement and helpful advice and Dr. Siraganian and the Hoon lab for valuable suggestions.

Correspondence should be addressed to Mark Hoon, Molecular Genetics Unit, Laboratory of Sensory Biology, National Institute of Dental and Craniofacial Health, National Institutes of Health, Building 49, Room 1A16, 49 Convent Drive, Bethesda MD 20892. E-mail: mark.hoon@nih.gov.

DOI:10.1523/JNEUROSCI.1533-12.2012

Copyright $\odot 2012$ the authors $\quad 0270-6474 / 12 / 328686-10 \$ 15.00 / 0$
}

Ladenheim et al., 2002). Additionally, immunolocalization studies showed that NMB protein is present in the dorsal horn of the spinal cord (Massari et al., 1983; Namba et al., 1985) and expression was also seen in sensory neurons (Wada et al., 1990). Intrathecal injection of NMB elicits nociceptive reflex responses, but the nature of the reaction produced is unclear (O'Donohue et al., 1984; De Koninck and Henry, 1989; Cridland and Henry, 1992). In contrast, GRP has been clearly demonstrated to be involved in itch sensation (Sun and Chen, 2007; Sun et al., 2009). GRPR knock-out mice, and animals in which GRPR-expressing neurons in the dorsal horn are eliminated, exhibit attenuated responses to most pruritic agents. Moreover, loss of GRPR or ablation of the GRPR-expressing neurons has no effect on other sensory modalities (Sun and Chen, 2007; Sun et al., 2009). This has led to the proposal that GRP is an itch-specific signaling neuropeptide and GRPR neurons in the dorsal horn represent a labeled line for itch

A direct approach to examine the central role of nociceptive neuropeptides is the targeted ablation of peptide receptors expressing neurons with saporin-conjugated peptides (Wiley and Lappi, 2003). The elimination of neurons expressing different neuropeptide receptors in the dorsal horn reveals that these cells are functionally heterogeneous; loss of spinal neurons expressing TacR1, NPY, $\mu$-opioid, and the galanin receptor generates mice that exhibit a variety of different deficits in processing nociceptive stimuli (Nichols et al., 1999; Kline and Wiley, 2008; Wiley et al., 2009; Lemons and Wiley, 2011). The differences in behavior of mice lacking different cell types highlights the distinct roles of diverse classes of dorsal horn neurons (excitatory and inhibitory interneurons and projection neurons) (Nichols et al., 1999; Kline and Wiley, 2008; Wiley et al., 2009; Lemons and Wiley, 2011).

To begin to characterize the role of NMB in sensory neurons, we have examined its effects on neurogenic inflammation. In addition, using a cell-ablation approach we have established a central function for NMB in the spinal cord. 
Table 1. Molecules identified by comparison of trigeminal ganglia and genticulate ganglion RNA transcripts

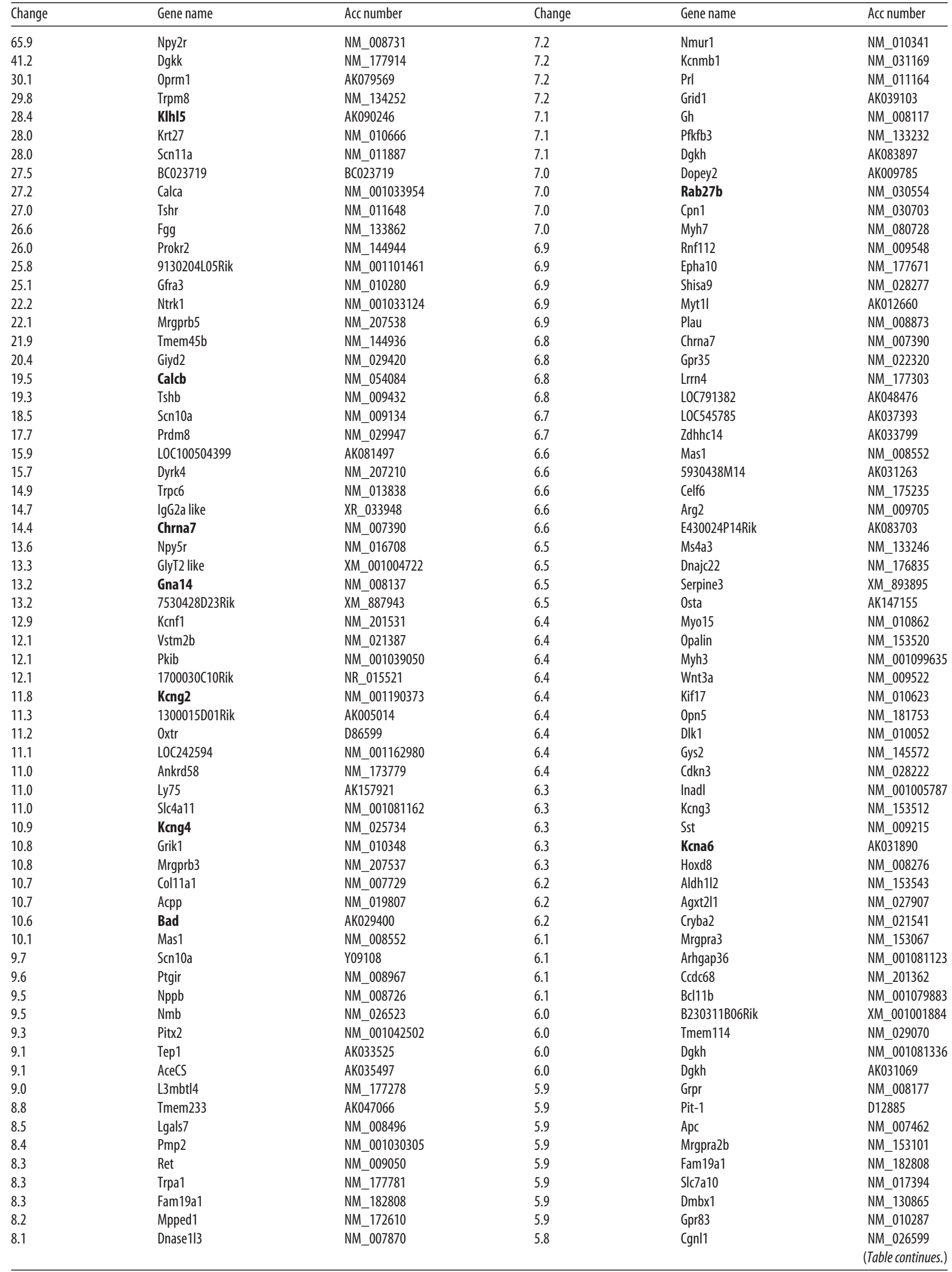


Table 1. Continued

\begin{tabular}{|c|c|c|c|c|c|}
\hline Change & Gene name & Acc number & Change & Gene name & Acc number \\
\hline 8.1 & Prkcq & NM_008859 & 5.8 & Fam188b2 & АК030561 \\
\hline 8.0 & Capn9 & NM_023709 & 5.8 & Fam19a1 & NM_182808 \\
\hline 7.9 & Gpr35 & NM_022320 & 5.7 & Syt16 & NM_172804 \\
\hline 7.8 & Ropn1 & NM_030744 & 5.7 & Lgi1 & NM_020278 \\
\hline 7.8 & Htr1a & NM_008308 & 5.6 & Rnf112 & NM_009548 \\
\hline 7.8 & Lpar3 & NM_022983 & 5.6 & Myh7 & NM_080728 \\
\hline 7.5 & Gsg1l & NM_001101488 & 5.6 & Tmem26 & NM_177794 \\
\hline 7.5 & Krt79 & NM_146063 & 5.6 & Robo3 & NM_001164767 \\
\hline 7.5 & Kiaa1239 & NM_177006 & 5.5 & Slc34a2 & NM_011402 \\
\hline 7.4 & Mal2 & NM_178920 & 5.5 & $\mathrm{BC}|2| 14$ & NM_025778 \\
\hline 7.4 & Syt5 & NM_016908 & 5.5 & Casc1 & AK034148 \\
\hline 7.4 & SIC5a1 & NM_019810 & & & \\
\hline
\end{tabular}

List of genes differentially expressed in trigeminal ganglia versus genticulate ganglion with fold -change $>2$ SD from the mean; $n=4$. ISH data are presented for genes highlighted in bold (see Fig. 1). Fold differences in expression (Change) and GenBank accession numbers (Acc number) are indicated.

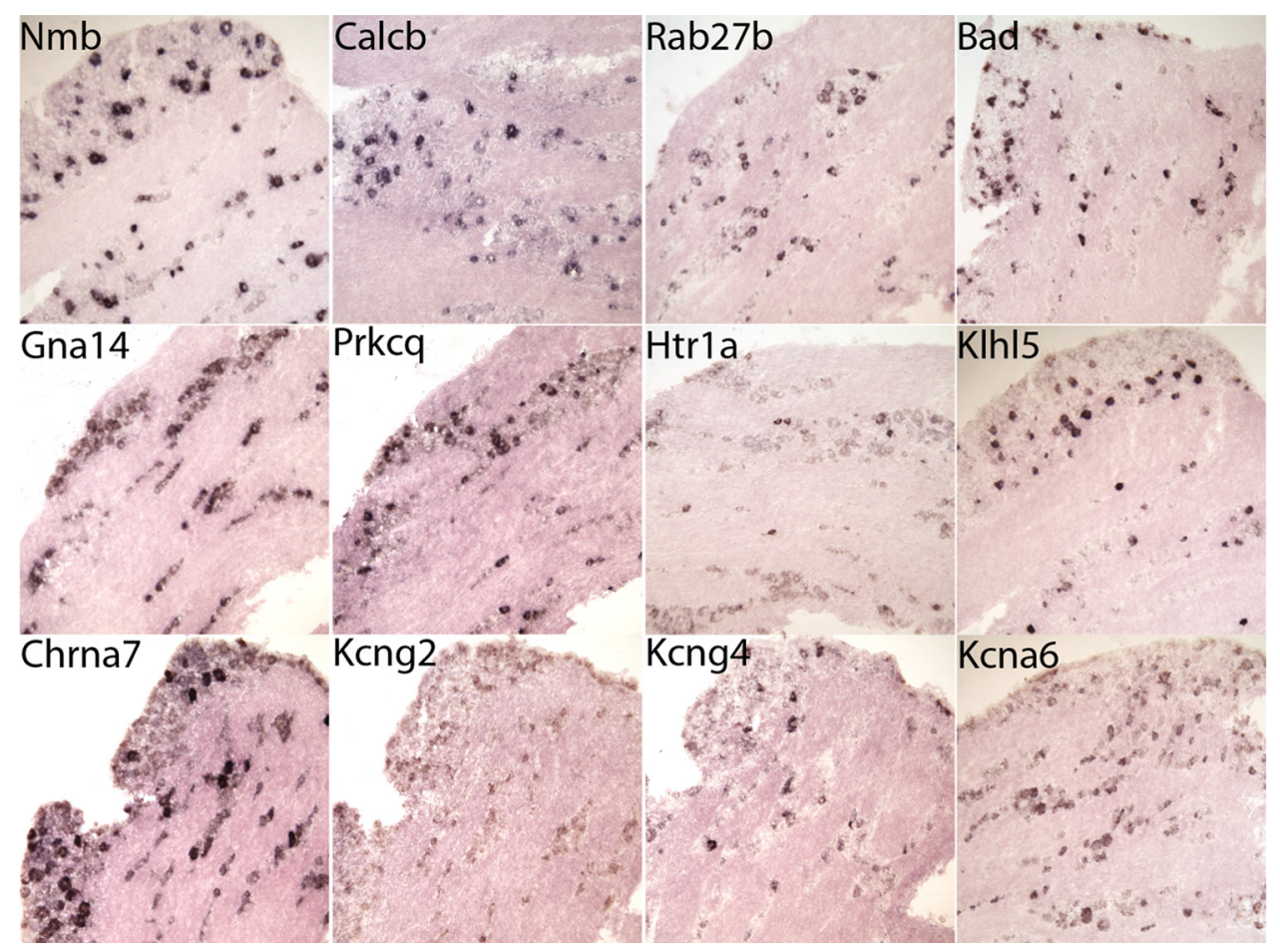

Figure 1. ISH reveals the expression pattern of genes identified in the differential screen of TG versus GG. Sections of TG were hybridized with probes to select molecules as indicated.

\section{Materials and Methods}

Animals. Mice were 25-30 g male C57BL/6 and Tg(Nmbr-EGFP) JG22Gsat (GENSAT Project at Rockefeller University). Procedures followed the National Institutes of Health (NIH) guidelines for the use and care of laboratory animals and were approved by the National Institute of Dental and Craniofacial Research Animal Care and Use Committee.

To eliminate specific subsets of dorsal horn interneurons $10 \mu \mathrm{g}$ of NMB-saporin or $0.13 \mu \mathrm{g}$ of stable SP-saporin (SSP-saporin) or $1.3 \mu \mathrm{g}$ of bombesin-saporin or $10 \mu \mathrm{g}$ of blank-saporin (20 $\mu \mathrm{l}$ of PBS; Advanced Targeting System) were administered to the lumbar 4-5 segments (Mishra and Hoon, 2010). Behavioral testing occurred between 1 and 3 weeks after toxin treatment. Tissue was harvested for expression analysis $7 \mathrm{~d}$ after injection of toxin.

Behavioral assays. For thermal responses, a radiant heat source was focused on the hindpaw and the time from the initiation until withdrawal was measured using an automated Hargreaves test apparatus (Ugo Basile). Animals were habituated for at least $30 \mathrm{~min}$ in individual chambers before experiments and a maximum cutoff of $20 \mathrm{~s}$ was used to prevent tissue damage. Using an automated von Frey apparatus (Ugo Basile), mechanical responses were assayed by determining the threshold force required to induce paw withdrawal. For itch assays, hair was removed from the lumbar back region and $100 \mathrm{~nm}$ of histamine trifluoromethyl toluidide (HTMT) was administered in a $10 \mu \mathrm{l}$ subcutaneous injection. Following administration of itch-inducing agent, numbers of itching bouts were counted over $30 \mathrm{~min}$.

To test for effects of neuropeptides $10 \mu \mathrm{l}$ of NMB $(50 \mu \mathrm{g})$ or $10 \mu \mathrm{l}$ of NMB $(50 \mu \mathrm{g})$ CGRP $(10 \mu \mathrm{g})$ and SP $(1 \mu \mathrm{g})$ were injected into the hindpaw. Thirty minutes after injection of peptides, paw edema was measured using a plethysmometer (IITC) and thermal and mechanical sensitization measured by Hargreaves and von Frey apparatus assays (Ugo Basile), respectively. We examined if pretreatment with peptide antagonists could prevent neurogenic inflammation. Ten minutes before inducing neurogenic inflammation, neuropeptide antagonists or vehicle control were administered via tail vein injection; $10 \mu \mathrm{g}$ of NMB antagonist BIM 23042 (Tocris Bioscience) or a mixture of $10 \mu \mathrm{g}$ BIM 23042, $10 \mu \mathrm{g}$ CGRP 8-37, and $1 \mu \mathrm{g}$ spantide were given as a single bolus (100 $\mu \mathrm{l}$ in PBS vehicle). BIM 23042 is a specific antagonist of the NMBR (Orbuch et al., 1993), CGRP 8-37 is an antagonist of the CGRP receptor (Deems et al., 1991; Wang et al., 1991), and spantide is an inhibitor of TacR1 (Folkers et al., 1984). Hindpaw reflex responses for thermal (Hargreaves) and mechanical stimuli (von Frey) and 

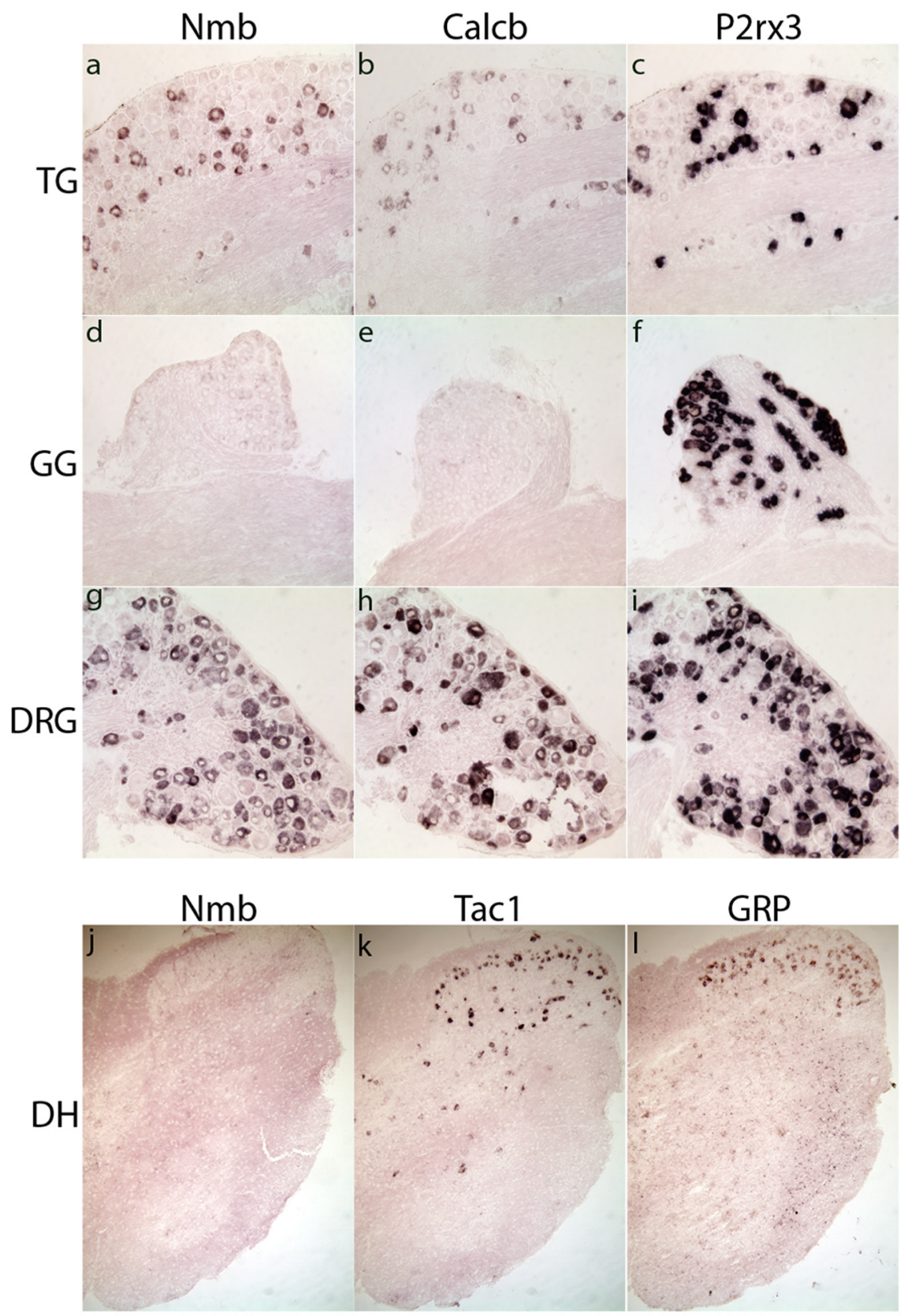

Figure 2. NMB is specifically expressed in a subset of TG and DRG neurons and is undetectable in the GG. ISH reveals that Nmb $(\boldsymbol{a}, \boldsymbol{d}, \boldsymbol{g})$ and $\mathrm{Calcb}(\boldsymbol{b}, \boldsymbol{e}, \boldsymbol{h})$ are expressed in the TG $(\boldsymbol{a}-\boldsymbol{c})$ and DRG $(\boldsymbol{g}-\boldsymbol{i})$, but are undetectable in the GG $(\boldsymbol{d}-\boldsymbol{f})$. In contrast, the ionotrophic ion-channel P2Rx3 is expressed in all ganglia $(\boldsymbol{c}, \boldsymbol{f}, \boldsymbol{i})$. ISH of sections through the spinal cord $(\boldsymbol{j}-\boldsymbol{I})$ establishes that Nmb $(j)$ is not expressed, while Tac1 $(\boldsymbol{k})$ and GRP $(\boldsymbol{I})$ are found in a small number of interneurons in the dorsal horn.

Table 2. Relative expression levels of neuropeptides in dorsal root ganglia

\begin{tabular}{llll}
\hline Mean expression & SD & Gene name & Neuropeptide \\
\hline 861.6 & 229 & Calca & CGRP \\
215.0 & 34 & Nmb & NMB \\
129.9 & 19 & Tac1 & SP \\
22.9 & 3.8 & Gal & Galanin \\
18.4 & 3.0 & Calcb & CGRP \\
\hline
\end{tabular}

Expression was determined in arbitrary units; data were normalized to median microarray values. Data represent means $\pm S D ; n=4$ arrays. CGRP, calcitonin gene-related peptide; NMB, neuromedin $B ; S P$, substance $P$.

changes in paw volume were assessed before treatment and $30 \mathrm{~min}$ after induction of inflammation with mustard oil (10 $\mu \mathrm{l} ; 1 \%$ in mineral oil). Increased paw volume to injection of neuropeptide or mustard oil was normalized to the untreated or mustard oil-treated condition, respectively.
To investigate the effects of inflammation on mechanical sensitivity, the plantar surface of the hindpaw was injected with $20 \mu \mathrm{l}$ of complete Freund's adjuvant (CFA; Sigma). Behavioral testing was performed $24 \mathrm{~h}$ after injection.

In situ hybridization and immunohistochemistry. In situ hybridization (ISH) was performed at high stringency (washed $30 \mathrm{~min}$, $0.2 \times \mathrm{SSC}, 70^{\circ} \mathrm{C}$ ) as described previously (Hoon et al., 1999). Probes were generated for genes of interest by PCR and Topo-cloned into pCRII (Invitrogen). Sequences of cloned genes were confirmed and in vitro transcription was used to generate antisense cRNA probes. ISH was used to detect select genes in the TG and DRG and TacR1 and GRPR-positive interneurons in the spinal cord. Immunohistochemistry with chicken anti-green fluorescent protein (GFP) (1:500; Abcam) was used to detect NMBR-positive neurons in Nmbr-EGFP mice. Development of immunopositive GFP signal was achieved with donkey anti-chicken HRPconjugated secondary antibody (Jackson Immunolabs) together with NovaRed. Analysis of ablation was performed on tissue collected from $\geq 3$ mice. For each mouse, numbers of positive neurons for each receptor were counted from $\geq 1016 \mu \mathrm{M}$ serial sections. Total numbers of neurons expressing receptor were calculated for each animal, averaged, and normalized to values from blank-saporin controls.

Double-label ISH/immunohistochemistry was developed with anti-digoxigenin antibodies coupled to alkaline phosphatase together with Fast Red. CGRP and TRPV1 were detected with anti-CGRP (1:200; Millipore Bioscience Research Reagents) and anti-TRPV1 antibodies (1:100; Millipore Bioscience Research Reagents) and developed with donkey anti-rabbit FITC (Jackson Immunolabs) (Adler et al., 2000). The ISH signal for Nmb is nuclear because the doubling-labeling technique preferentially detects unspliced nuclear transcripts. Quantization of NMB overlap with CGRP and TRPV1 was performed by counting positive neurons from more than four sections for each double staining. Images were collected using a Microphot FX microscope (Nikon) and a Zeiss LSM 510 confocal microscope and processed using Adobe Photoshop.

Gene array analysis. Total RNA was isolated from TG, DRG, or geniculate ganglion (GG) using an RNeasy minikit (Qiagen). cDNA was synthesized from total RNA and used as a template to produce a cy5-labeled cRNA probe following protocols recommended by the manufacturer (Agilent). Gene arrays (GE4 $\times 44 \mathrm{~K} \mathrm{~V} 2$; Agilent) were hybridized, washed, and scanned as recommended by the manufacturer. Data were analyzed using Gene Spring (version 11) software.

Heterologous expression of NMBR and GRPR. Full-length NMBR and GRPR were amplified from brain cDNA and cloned into mammalian expression vector pEAK8 (Egde Biosystems). HEK-293 cells were transiently transfected with pEAK8-NMBR-ires-EGFP or pEAK8-GRPR and pEAK8-GFP using the Trans-it-293 kit in 24-well culture plates as recommended by the manufacturer (Mirus). Twenty-four hours after transfection, $20 \mu \mathrm{g} / \mathrm{ml}$ of NMB-saporin or blank-saporin or $2.5 \mu \mathrm{g} / \mathrm{ml}$ of bombesin-saporin were added to cultured media and $48 \mathrm{~h}$ later fields of live cells were photographed and GFP-positive cells counted. Cells were also stained with the vital stain propidium iodide to measure cell viabil- 
ity. Images were collected from at least four randomly chosen fields of cells from three independent experiments, and data were normalized versus untreated cells.

\section{Results}

We set out to identify novel molecules involved in detection and signaling processes of somatosensory neurons and used mouse whole genome microarrays to analyze genes expressed in the TG. To subtract genes expressed in glia and molecules involved in the general housekeeping functions, we compared gene expression profiles of TG with GG. Unlike the TG, which is composed of neurons that detect as well as transmit somatosensory input, the neurons in the GG are only involved in transmitting signals from taste buds. Table 1 lists genes we identified with TG versus GG differential expression > 5.5 (genes whose expression is highly significant with $>2$ SDs from the mean). As expected, many of the molecules we uncovered have been identified previously and are known to be important in somatosensation, e.g., $\operatorname{TrpM} 8, \operatorname{Tr} p A 1$, Scn10a, Scn1la, Mrgpcr, and neurotrophic factor receptors. To identify genes likely to be involved in mediating responses to specific stimuli, we examined the expression patterns of selected molecules by ISH, looking for genes expressed in a subsets of neurons (Fig. 1). Among the molecules prominently enriched and expressed in subsets of neurons were neuropeptides (Fig. 1). One of the neuropeptides we found was NMB. As expected from its differential expression, NMB is expressed in the TG and DRG but is not detectable by ISH in the GG (Fig. 2). The level of expression of NMB estimated from normalized gene array data indicates it is expressed at a level similar to CGRP (Calca and Calcb) and SP (Tac1) (Table 2). Previously, immunological methods were used to show NMB fibers, but no cell bodies were observed in the spinal cord (Massari et al., 1983; Namba et al., 1985). We confirmed using ISH that there are no NMB-expressing cells in the spinal cord (Fig. 2j). In contrast, mRNA transcripts for tachykinin (Tac1) and GRP are expressed in neurons in the dorsal horn as recently reported (Polgár et al., 2006; Koga et al., 2011)(Fig. $2 k, l)$. The studies characterizing immunopositive NMB fibers in the spinal cord (Massari et al., 1983; Namba et al., 1985) are consistent with this staining due to afferent projections of DRG neurons.

The function of NMB in somatosensation is still not fully understood, therefore, we focused our studies on this neuropeptide. Initially, we examined the expression pattern of NMB relative to two markers of nociceptive cells: CGRP and TRPV1. Double-label ISH/immunochemistry was used to determine the overlap in expression. Figure 3 shows an overlap of NMB and CGRP expression, $\sim 25 \%$ of NMB-expressing neurons coexpress CGRP (mean 26\% \pm 2.7 ), similar to the partial super- imposition of CGRP and SP (data not shown). In addition, we found NMB expression overlaps with TRPV1-positive cells $(24 \% \pm 2.6 \mathrm{NMB}$-cells coexpress TRPV1; Fig. $3 b)$. Thus, NMB is present in a subset of nociceptive sensory neurons.

\section{Peripheral role for NMB}

Release of CGRP and SP from sensory neurons elicits peripheral vasodilation and extravasation via stimulation of endothelial cells and also induces local hyperalgesia (Brain and Cox, 2006). To examine if NMB can cause swelling and sensitization, we performed injections of NMB into the plantar surface of the hindpaw of mice. Injection of $\mathrm{NMB}$ produced a significant enlargement of the foot and swelling was increased further by coadministration with SP and CGRP (Fig. 4a). Withdrawal latencies to thermal and mechanical stimulation were also decreased upon injection of NMB (Fig. $4 b, c$ ). In addition, coinjection of NMB, SP, and CGRP elicited greater hyperalgesia than NMB alone (Fig. $4 b, c)$. These results indicate NMB can cause local swelling and induce sensitization of peripheral neurons.

To determine whether release of NMB is involved in peripheral sensitization, we examined if neurogenic inflammatory 

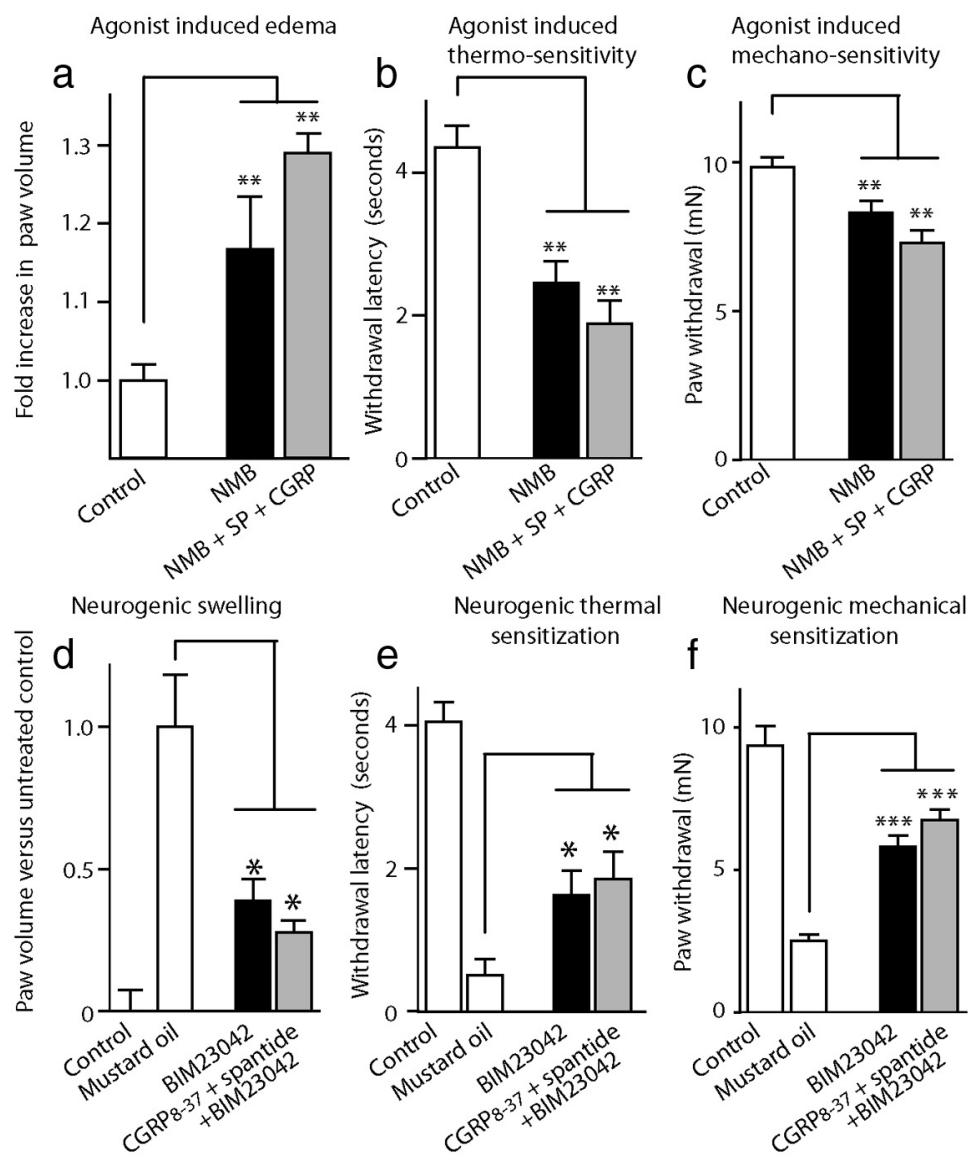

Figure 4. Injection of NMB induces edema and hyperalgesia and administration of NMB antagonist attenuates mustard oilinduced neurogenic inflammation. To determine the effects of NMB and BIM 23042, paw volume was measured by plethysmometry $(\boldsymbol{a}, \boldsymbol{d})$, thermal sensitization was assayed using the Hargreaves test $(\boldsymbol{b}, \boldsymbol{e})$, and mechanical hyperalgesia was quantified using von Frey microfilament measurements $(\boldsymbol{c}, \boldsymbol{f})$. Hindpaws were injected with NMB or NMB, SP, and CGRP as indicated $(\boldsymbol{a}-\boldsymbol{c})$. Pretreatment of mice with NMB antagonist BIM 23042, or BIM 23042, CGRP8 -37, and spantide dramatically reduces mustard oil-induced swelling and hyperalgesia compared with vehicle-treated animals $(\boldsymbol{d}-\boldsymbol{f})$. Data represent means \pm SEM; $n \geq 6$ animals; significant differences between treatments (Student's t test) are indicated by ${ }^{*} p<0.05,{ }^{* *} p<0.01$, and ${ }^{* * *} p<0.001$.

events can be prevented by pretreatment with the specific NMBantagonist BIM 23042 (Orbuch et al., 1993). We activated peripheral nerves in the foot by injection of mustard oil and measured the effectiveness of antagonist to block swelling and hyperalgesia. Figure 4 shows that BIM 23042 attenuates neurogenic swelling and thermal and mechanical sensitization, demonstrating NMB contributes to neurogenic inflammation upon activation of peripheral nerve fibers. Combined pretreatment with antagonists for NMB, SP, and CGRP produced the greatest reduction of neurogenic inflammation with an $\sim 70 \%$ reduction in swelling and $40 \%$ attenuation of sensitization.

\section{Central role for NMB}

Many neuropeptides act centrally by activating receptors expressed in the postsynaptic membranes of interneurons in the dorsal horn (Hökfelt, 1991; De Felipe et al., 1998; Salio et al., 2006). Therefore, we examined if the receptor for NMB is expressed in cells in the dorsal horn of the spinal cord. To visualize the NMBR, we made use of Nmbr-GFP transgenic mice (Gong et al., 2003). Revealingly, we found that NMBR is expressed in a small number of neurons in the superficial layers of the dorsal horn (Fig. 5a). The NPY and galanin peptide receptors have also been shown to be expressed in sensory neurons (Zhang et al., 1997, 1998; Landry et al., 2000). Therefore, we also investigated if
NMBR is expressed in sensory neurons and found a subset of NMBR-positive cells in DRG (Fig. 5b).

A useful approach to examine the function of neurons that express peptide receptors (Wiley and Lappi, 2003) is to use specific toxins to ablate these cells. Therefore, we synthesized a targeted toxin against NMBR by conjugating carboxy-amidated NMB with the ribosome-inactivating protein saporin. To determine the specificity of this reagent, we tested toxin on cells that heterologously express NMBR or GRPR. Expression of receptors was performed in HEK-293 cells, and the effectiveness of toxin treatment was determined by measuring loss of GFP fluorescent cells (GFP was cotranscribed with receptor). Figure 5 shows that HEK-293 cells expressing NMBR were efficiently ablated following application of NMB-saporin. In contrast, GRPR-transfected cells were not killed by NMB-saporin (Fig. 5e). As expected, bombesin-saporin-conjugated toxin eliminated GRPR-transfected cells, but did not reduce numbers of NMBR-expressing cells (Fig. 5f). Therefore, NMB-saporin is a selective ablation agent for NMBR-expressing cells.

Ablation of TacR1 and GRPRexpressing neurons in the dorsal horn leads to the selective loss of thermal and mechanical nociceptive responses or itch responses, respectively (Nichols et al., 1999; Sun et al., 2009). Since NMB and GRP have similar signaling roles in the CNS (Battey and Wada, 1991; OhkiHamazaki et al., 1999; Ladenheim et al., 2002), we were interested if there is overlap in the function of NMBR and GRPR neurons in somatosensory signaling. We determined that a dose of $10 \mu \mathrm{g}$ NMB-saporin was effective at ablating $\sim 80 \%$ of NMBR-expressing neurons. Importantly, toxin treatment did not reduce numbers of DRG neurons expressing NMBR. After administration of toxin, animals were injected subcutaneously at the lumbar back region with histamine agonist HTMT and the number of scratching bouts determined. Itch responses of animals given NMB-saporin were not significantly reduced compared with control animals, whereas bombesin-saporin treatment led to a dramatic reduction of responses (Fig. 6a). Thus, NMBR neurons are not required for responses to pruritic substances. Since NMB is expressed in many TRPV1 sensory neurons, we reasoned that the loss of NMBR neurons might have an effect on responses to heat. Thus, we tested mice using the Hargreaves test (Fig. 6b). NMB-saporintreated mice exhibited considerably less sensitivity to heat stimulus with response latencies approximately twice as long as blank saporin-treated controls (Fig. 6b). In addition, it has been shown that SSP-saporin treatment produces deficits in reaction to mechanical stimulation (Nichols et al., 1999). Therefore, to measure responses to noxious mechanical stimuli, we induced inflammation in the plantar surface of the foot with CFA and used von Frey microfilaments to measure mechanical sensitivity. As expected, 
NMBR-neurons in DH

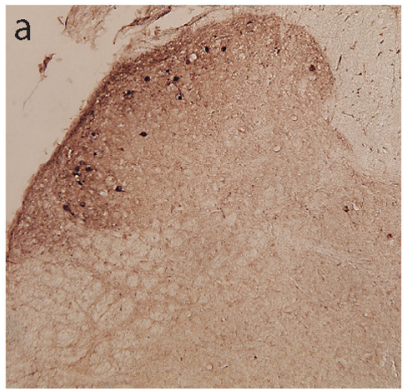

NMBR-transfected cells
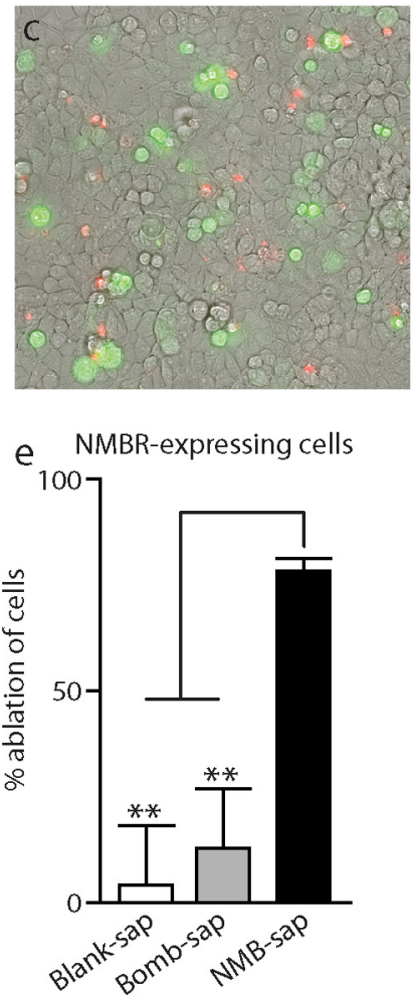

NMBR-neurons in DRG

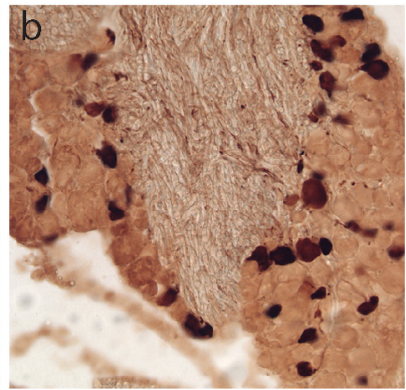

NMB-sap treated NMBR-cells

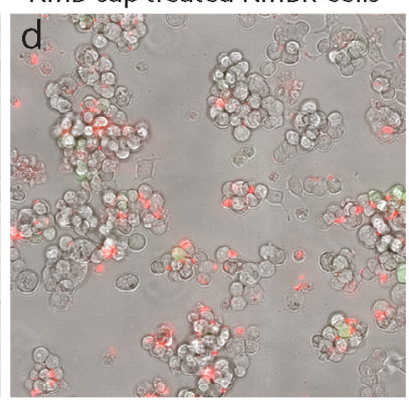

$f$

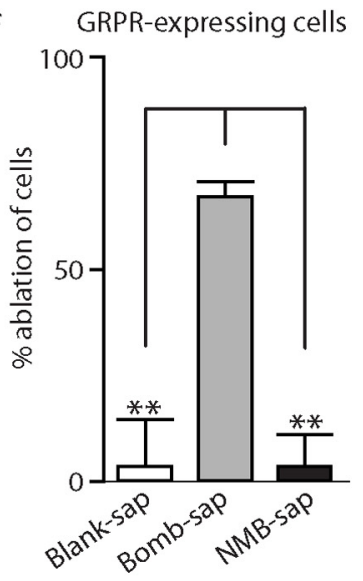

Figure 5. NMBR is expressed in the dorsal horn of the spinal cord and DRG; NMB-saporin selectively ablates NMBR-expressing cells. Immunostaining of sections through dorsal horn (DH) of the spinal cord (a) and DRG $(\boldsymbol{b})$ from $\mathrm{Tg}(\mathrm{Nmbr}$-EGFP) mice detects cells expressing NMBR. Brightfield images were captured for fields of HEK-293 cells expressing NMBR-ires-GFP $(\boldsymbol{c}, \boldsymbol{d})$. Untreated (c) and NMB-saporin (NMB-sap)-treated cells $(\boldsymbol{d})$ were counterstained with vital stain propidium iodide (red) to illustrate the increase in nonviable cells following administration of toxin. Quantification of the ablation of cells expressing NMBR (e) or GRPR $(\boldsymbol{f})$ was measured by the loss of GFP fluorescent cells normalized to untreated controls. NMB-sap results in efficient ablation while bombesin-saporin (Bomb-sap) or blank-saporin (blank-sap) have no effect on NMBR-expressing cells. Cells transfected with GRPR were successfully eliminated with bombesin-saporin, whereas NMB-saporin and blank-saporin treatment did not alter numbers of GRPR-expressing cells. Data represent means $\pm \mathrm{SEM} ; n \geq 3$ independent experiments; significant differences between treatments (Student's $t$ test) are indicated by ${ }^{* *} p<0.001$.

SSP-saporin-injected animals showed reduced reaction to noxious mechanical force (Nichols et al., 1999)(Fig. 6c). In contrast, NMB-saporin-treated mice exhibited reflex responses similar to control animals (Fig. 6c). In summary, eliminating NMBRexpressing neurons produces a reduction of responses to heat, but no change in reaction to itch or noxious mechanical stimulation.

Given the distinct phenotype of mice with reduced numbers of neurons expressing NMBR, GRPR, and TacR1, we were interested in determining the effectiveness of toxins in eliminating cells expressing these receptors in the dorsal horn of the spinal cord. Examination of sections of untreated animals showed the numbers of NMBR- and GRPR-expressing neurons was approximately the same (Fig. $7 a, c$; mean of $14.2 \pm 0.7$ cells $/ 16 \mu \mathrm{M} \mathrm{sec}$ tions in the lumbar spinal cord for NMBR and $9.0 \pm 0.6$ cells for GRPR). While NMBR and GRPR neurons are present predominantly in the superficial layers of the spinal cord, TacR1 is found in approximately four times as many cells throughout this region and also in deeper areas. For this reason we chose to score TacR1positive neurons in laminar layer I through IV (mean of $43.8 \pm$ 1.9 cells/16 $\mu \mathrm{M}$ sections in the lumbar spinal cord for TacR1). Injection of blank-saporin did not reduce numbers of NMBR-, GRPR-, or TacR1-positive neurons. Quantization of neurons expressing NMBR revealed that NMB-saporin treatment leads to loss of most NMBR-expressing neurons (Fig. $7 d, g$ ). As expected from our behavioral results, bombesin-saporin treatment does not significantly reduce numbers of NMBR-positive neurons but ablates GRPR-expressing neurons (Fig. 7e,h). SSP-saporin was less effective at eliminating TacR1-expressing cells, but, interestingly, numbers of NMBR-expressing neurons were reduced $\sim 65 \%$ after injection with this toxin (Fig. $7 g$ ). In addition, NMB toxin results in the elimination of significant numbers of TacR1positive cells (including most lamina I neurons; Fig. $7 g$ ). These results indicate that there is a partial overlap in the expression of NMBR and TacR 1 and suggests there are two separate classes of interneurons: cells that express NMBR and TacR 1 and neurons that express GRPR but not NMBR or TacR1.

\section{Discussion}

We set out to discover new somatosensory signaling molecules in the TG. By comparing genes transcribed in two functionally distinct ganglia, we identified a small number of novel genes and validated their expression by ISH. These genes are presented in Table 1, and offer a resource of TG-specific candidate signaling molecules for the somatosensory research community. Some of the genes uncovered were expressed in subsets of neurons, suggestive of a modality-specific role (Fig. 1). The significance of these molecules is emphasized by their relative expression levels compared with known signaling molecules like TRPA1 and TRPM8 (McKemy et al., 2002; Peier et al., 2002; Story et al., 2003; Jordt et al., 2004). A number of molecules we identified could well be components of signaling pathways that have been previously partially characterized. For other molecules, further work will be needed to assign definitive functions. Our screen also revealed neuropeptides highly expressed in TG, including NMB. Although the function of NMB in the CNS has been studied (Battey and Wada, 1991; Ohki-Hamazaki et al., 1999; Ladenheim et al., 2002), its role in the peripheral nervous system is not clear (O'Donohue et al., 1984; De Koninck and Henry, 1989; Cridland and Henry, 1992), therefore, we performed experiments to better understand its function.

Peripheral sensory neurons are classified histologically and functionally as "peptidergic" or "nonpeptidergic" (Snider and McMahon, 1998; Patapoutian and Reichardt, 2001). We found that NMB is expressed with CGRP and TRPV1 (Fig. 3); therefore, NMB must be coexpressed also with SP in many neurons. A possible explanation for the coexpression of peptides is that they have partially redundant functions, and they combine to produce their effects. This concept is supported by the partial nociceptive phenotypes of mice lacking CGRP and SP (Cao et al., 1998; Salmon et al., 2001, 2004). Our studies also suggest that these neuropeptides combine to induce hyperalgesia and neurogenic swelling at a site of injury (Fig. 4). An additional potential role for 

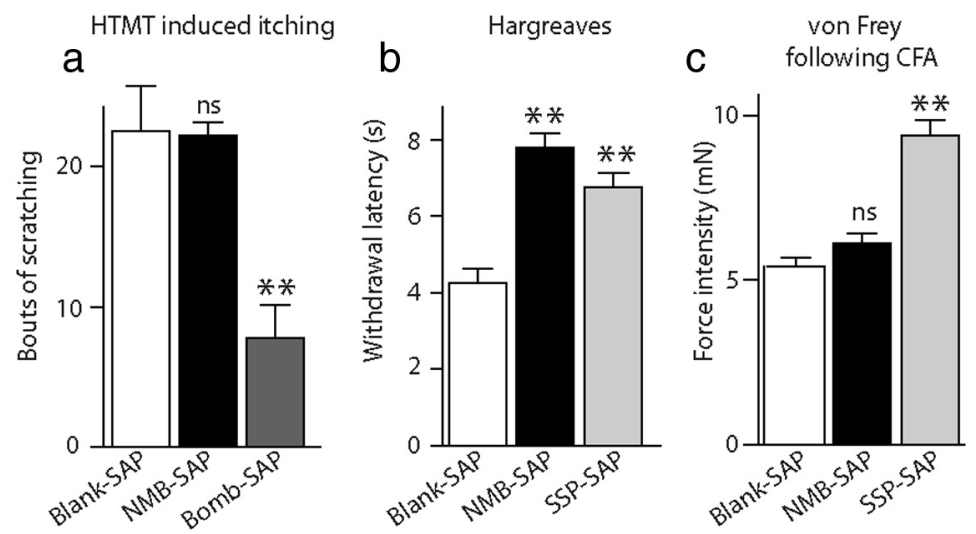

Figure 6. Ablation of NMBR-expressing dorsal horn neurons produces a selective deficit in noxious heat sensation. Itch sensation was assayed by quantitating bouts of itching following subcutaneous injection of the histamine agonist HTMT (a). Paw withdrawal latency was used to monitor thermal sensitivity $(\boldsymbol{b})$ and mechanical sensitivity was measured using a von Frey device after sensitization of the paw with CFA (c). Intrathecal injection of bombesin-saporin (Bomb-sap) attenuates pruritic reaction, but NMB-saporin (NMB-sap) and blank-saporin (Blank-sap) do not alter itch responses compared with untreated controls. Administration of NMB-saporin resulted in an increased latency in response to thermal stimulation but did not change mechanical sensitivity. In contrast, SSP-saporin (SSP-sap) treatment led to attenuation of responses to both mechanical and noxious heat stimuli. Data represent means $\pm S E M ; n \geq 6$ animals; significant differences between untreated controls and treatments (Student's $t$ test) are indicated by ${ }^{* *} p<0.01$

$\mathrm{NMB}$ could be in feedback processes. Indeed, we find the receptor for NMB is expressed in sensory neurons; therefore, these cells could be activated by NMB (Fig. 5).

In addition to its role in the periphery, we discovered that $\mathrm{NMB}$, akin to its bombesin family counterpart GRP, is probably also involved as a central neurotransmitter. We found that the receptor for NMB is present in neurons in the superficial lamina of the spinal cord (Fig. 5). When NMBR-expressing neurons are eliminated, there was no change in itch responses (Fig. 6). Therefore, $\mathrm{NMB}$ is not involved in pruritic signaling. Revealingly, NMB-saporin-treated mice exhibited specific attenuation of responses to heat (Fig. 6), consistent with the expression of NMB in TRPV1 neurons. The multiple neuropeptide expressed in the same neurons, the moderate blocking effects of individual antagonists (Lecci et al., 1991; Birch et al., 1992), and the partial phenotypes of neuropeptide knock-out mice (Cao et al., 1998; Salmon et al., 2001, 2004) all point to functional redundancy between nociceptive neuropeptides. Thus, for NMBR antagonists to be effective at ameliorating pain they will probably need to be combined with antagonists to other peptides or other therapeutic targets.

NMB-saporin administration attenuates responses to heat, but has no effect on noxious mechanical responses, demonstrating that NMBR-expressing neurons are selective for responses to thermal stimuli (Fig. 6). Moreover, we found indirect evidence that there is partial coexpression of NMBR with TacR1 (Fig. 7). TacR1-expressing neurons have previously been shown to be required for processing noxious thermal and mechanical pain (Nichols et al., 1999). This suggests that NMBR-TacR1expressing cells could represent a specific class of interneuron involved in processing thermal heat reception. Sensory neurons send axons centrally, forming synapses with neurons in the dorsal horn of the spinal cord, with most nociceptive input occurring in the most superficial lamina. Recent molecular genetic studies demonstrate functionally defined subsets of sensory neuron target-specific lamina in the dorsal horn (Zylka et al., 2005; Liu et al., 2007; Seal et al., 2009; Li et al., 2011). These studies suggest that sensory afferents are topologically organized, with input of specific sensory modalities forming circuits with specific classes of interneurons found in particular zones of the spinal cord. Thus, our studies extend the concept that input into the dorsal horn is defined by selective connections and lays the foundation for future studies exploring the specificity of dorsal horn circuits.

In summary, we have identified NMB as both an agent that contributes to neurogenic inflammation and a potential neurotransmitter used by thermal nociceptive receptors.

\section{References}

Adler E, Hoon MA, Mueller KL, Chandrashekar J, Ryba NJ, Zuker CS (2000) A novel family of mammalian taste receptors. Cell 100:693-702.

Battey J, Wada E (1991) Two distinct receptor subtypes for mammalian bombesin-like peptides. Trends Neurosci 14:524-528.

Bergman E, Johnson H, Zhang X, Hökfelt T, Ulfhake B (1996) Neuropeptides and neurotrophin receptor mRNAs in primary sensory neurons of aged rats. J Comp Neurol 375:303-319.

Birch PJ, Harrison SM, Hayes AG, Rogers H, Tyers MB (1992) The non-peptide NK1 receptor antagonist, (+/-)-CP-96,345, produces antinociceptive and antioedema effects in the rat. Br J Pharmacol 105:508-510.

Brain SD, Cox HM (2006) Neuropeptides and their receptors: innovative science providing novel therapeutic targets. Br J Pharmacol 147 [Suppl] 1:S202-S211

Cao YQ, Mantyh PW, Carlson EJ, Gillespie AM, Epstein CJ, Basbaum AI (1998) Primary afferent tachykinins are required to experience moderate to intense pain. Nature 392:390-394.

Corjay MH, Dobrzanski DJ, Way JM, Viallet J, Shapira H, Worland P, Sausville EA, Battey JF (1991) Two distinct bombesin receptor subtypes are expressed and functional in human lung carcinoma cells. J Biol Chem 266:18771-18779.

Cridland RA, Henry JL (1992) Bombesin, neuromedin C and neuromedin B given intrathecally facilitate the tail flick reflex in the rat. Brain Res 584:163-168.

Deems RO, Cardinaux F, Deacon RW, Young DA (1991) Amylin or CGRP (8-37) fragments reverse amylin-induced inhibition of ${ }^{14} \mathrm{C}$-glycogen accumulation. Biochem Biophys Res Commun 181:116-120.

De Felipe C, Herrero JF, O’Brien JA, Palmer JA, Doyle CA, Smith AJ, Laird JM, Belmonte C, Cervero F, Hunt SP (1998) Altered nociception, analgesia and aggression in mice lacking the receptor for substance P. Nature 392:394-397.

De Koninck Y, Henry JL (1989) Bombesin, neuromedin B and neuromedin C selectively depress superficial dorsal horn neurones in the cat spinal cord. Brain Res 498:105-117.

Folkers K, Håkanson R, Hörig J, Xu JC, Leander S (1984) Biological evaluation of substance P antagonists. Br J Pharmacol 83:449-456.

Gong S, Zheng C, Doughty ML, Losos K, Didkovsky N, Schambra UB, Nowak NJ, Joyner A, Leblanc G, Hatten ME, Heintz N (2003) A gene expression atlas of the central nervous system based on bacterial artificial chromosomes. Nature 425:917-925.

Heasley LE (2001) Autocrine and paracrine signaling through neuropeptide receptors in human cancer. Oncogene 20:1563-1569.

Hökfelt T (1991) Neuropeptides in perspective: the last ten years. Neuron 7:867-879

Hoon MA, Adler E, Lindemeier J, Battey JF, Ryba NJ, Zuker CS (1999) Putative mammalian taste receptors: a class of taste-specific GPCRs with distinct topographic selectivity. Cell 96:541-551.

Jensen RT, Battey JF, Spindel ER, Benya RV (2008) International Union of Pharmacology. LXVIII. Mammalian bombesin receptors: nomenclature, distribution, pharmacology, signaling, and functions in normal and disease states. Pharmacol Rev 60:1-42.

Jordt SE, Bautista DM, Chuang HH, McKemy DD, Zygmunt PM, Högestätt 
ED, Meng ID, Julius D (2004) Mustard oils and cannabinoids excite sensory nerve fibres through the TRP channel ANKTM1. Nature 427:260-265.

Kline RH 4th, Wiley RG (2008) Spinal muopioid receptor-expressing dorsal horn neurons: role in nociception and morphine antinociception. J Neurosci 28:904-913.

Koga K, Chen T, Li XY, Descalzi G, Ling J, Gu J, Zhuo M (2011) Glutamate acts as a neurotransmitter for gastrin releasing peptidesensitive and insensitive itch-related synaptic transmission in mammalian spinal cord. Mol Pain 7:47.

Ladenheim EE, Hampton LL, Whitney AC, White WO, Battey JF, Moran TH (2002) Disruptions in feeding and body weight control in gastrin-releasing peptide receptor deficient mice. J Endocrinol 174:273-281.

Landry $\mathrm{M}$, Holmberg $\mathrm{K}$, Zhang X, Hökfelt T (2000) Effect of axotomy on expression of NPY, galanin, and NPY Y1 and Y2 receptors in dorsal root ganglia and the superior cervical ganglion studied with double-labeling in situ hybridization and immunohistochemistry. Exp Neurol 162:361-384.

Lecci A, Giuliani S, Patacchini R, Viti G, Maggi CA (1991) Role of NK1 tachykinin receptors in thermonociception: effect of (+/-)-CP 96,345, a non-peptide substance $P$ antagonist, on the hot plate test in mice. Neurosci Lett 129:299-302.

Lemons LL, Wiley RG (2011) Galanin receptorexpressing dorsal horn neurons: Role in nociception. Neuropeptides 45:377-383.

Li L, Rutlin M, Abraira VE, Cassidy C, Kus L, Gong S, Jankowski MP, Luo W, Heintz N, Koerber HR, Woodbury CJ, Ginty DD (2011) The functional organization of cutaneous low-threshold mechanosensory neurons. Cell 147:1615-1627.

Liu Q, Vrontou S, Rice FL, Zylka MJ, Dong X, Anderson DJ (2007) Molecular genetic visualization of a rare subset of unmyelinated sensory neurons that may detect gentle touch. Nat Neurosci 10:946-948.

Massari VJ, Tizabi Y, Park CH, Moody TW, Helke CJ, O’Donohue TL (1983) Distribution and origin of bombesin, substance $P$ and somatostatin in cat spinal cord. Peptides 4:673-681.

McKemy DD, Neuhausser WM, Julius D (2002) Identification of a cold receptor reveals a general role for TRP channels in thermosensation. Nature 416:52-58.

Mishra SK, Hoon MA (2010) Ablation of TrpV1 neurons reveals their selective role in thermal pain sensation. Mol Cell Neurosci 43:157-163.

Namba M, Ghatei MA, Gibson SJ, Polak JM, Bloom SR (1985) Distribution and localization of neuromedin B-like immunoreactivity in pig, cat and rat spinal cord. Neuroscience 15:1217-1226.

Nichols ML, Allen BJ, Rogers SD, Ghilardi JR, Honore P, Luger NM, Finke MP, Li J, Lappi DA, Simone DA, Mantyh PW (1999) Transmission of chronic nociception by spinal neurons expressing the substance P receptor. Science 286:1558-1561.

O’Donohue TL, Massari VJ, Pazoles CJ, Chronwall BM, Shults CW, Quirion R, Chase TN, Moody TW (1984) A role for bombesin in sensory processing in the spinal cord. J Neurosci 4:2956-2962.

Ohki-Hamazaki H, Sakai Y, Kamata K, Ogura H, Okuyama S, Watase K, Yamada K, Wada K (1999) Functional properties of two bombesin-like peptide receptors revealed by the analysis of mice lacking neuromedin B receptor. J Neurosci 19:948-954.

Orbuch M, Taylor JE, Coy DH, Mrozinski JE Jr, Mantey SA, Battey JF, Moreau JP, Jensen RT (1993) Discovery of a novel class of neuromedin B receptor antagonists, substituted somatostatin analogues. Mol Pharmacol 44:841-850. $\begin{array}{lll}\text { NMBR } & \text { GRPR } & \text { TacR1 }\end{array}$
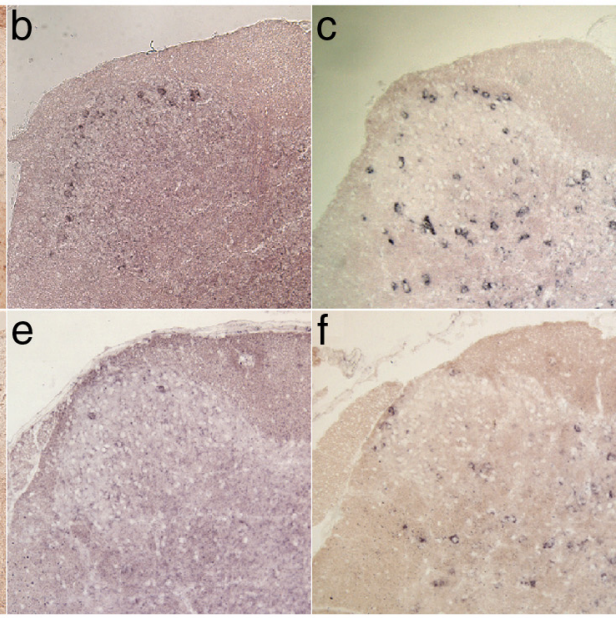

Bombesin-saporin

SSP-saporin

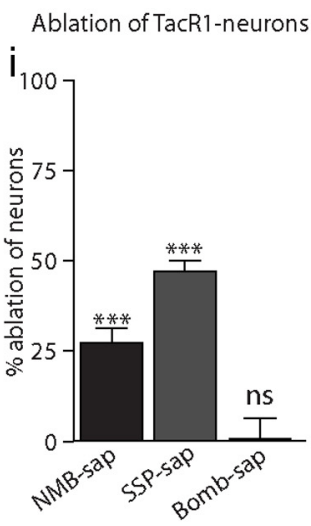

Figure 7. NMBR is expressed in a specific class of dorsal horn interneurons separated from GRPR-expressing neurons. Sections

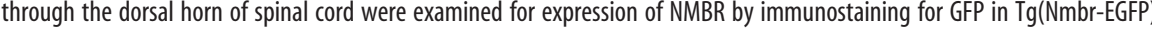
(ISH was used to determine cells positive for GRPR $(\boldsymbol{b}, \boldsymbol{e}, \boldsymbol{h})$ and TacR1 $(\boldsymbol{c}, \boldsymbol{f}, \boldsymbol{i})$. NMBR, GRPR, and TacR1 are (d) and treatment with specific conjugated peptide saporin (as indicated) led to ablation of most of (NMB-sap) and SSP-saporin (SSP-sap) greatly reduces their numbers, but bombesin-saporin (Bomb作 effect (i). Data represent means \pm SEM of the levels of ablation relative to untreated control samples; $n \geq 3$ animals; significant differences between treatments and untreated animals (Student's $t$ test) are indicated by ${ }^{* * *} p<0.001$.

Patapoutian A, Reichardt LF (2001) Trk receptors: mediators of neurotrophin action. Curr Opin Neurobiol 11:272-280.

Peier AM, Moqrich A, Hergarden AC, Reeve AJ, Andersson DA, Story GM, Earley TJ, Dragoni I, McIntyre P, Bevan S, Patapoutian A (2002) A TRP channel that senses cold stimuli and menthol. Cell 108:705-715.

Polgár E, Furuta T, Kaneko T, Todd A (2006) Characterization of neurons that express preprotachykinin $\mathrm{B}$ in the dorsal horn of the rat spinal cord. Neuroscience 139:687-697.

Salio C, Lossi L, Ferrini F, Merighi A (2006) Neuropeptides as synaptic transmitters. Cell Tissue Res 326:583-598.

Salmon AM, Damaj MI, Marubio LM, Epping-Jordan MP, Merlo-Pich E, Changeux JP (2001) Altered neuroadaptation in opiate dependence and neurogenic inflammatory nociception in alpha CGRP-deficient mice. Nat Neurosci 4:357-358.

Salmon AM, Evrard A, Damaj I, Changeux JP (2004) Reduction of withdrawal signs after chronic nicotine exposure of alpha-calcitonin generelated peptide knock-out mice. Neurosci Lett 360:73-76.

Seal RP, Wang X, Guan Y, Raja SN, Woodbury CJ, Basbaum AI, Edwards RH (2009) Injury-induced mechanical hypersensitivity requires C-low threshold mechanoreceptors. Nature 462:651-655.

Snider WD, McMahon SB (1998) Tackling pain at the source: new ideas about nociceptors. Neuron 20:629-632.

Story GM, Peier AM, Reeve AJ, Eid SR, Mosbacher J, Hricik TR, Earley TJ, 
Hergarden AC, Andersson DA, Hwang SW, McIntyre P, Jegla T, Bevan S, Patapoutian A (2003) ANKTM1, a TRP-like channel expressed in nociceptive neurons, is activated by cold temperatures. Cell 112:819-829.

Sun YG, Chen ZF (2007) A gastrin-releasing peptide receptor mediates the itch sensation in the spinal cord. Nature 448:700-703.

Sun YG, Zhao ZQ, Meng XL, Yin J, Liu XY, Chen ZF (2009) Cellular basis of itch sensation. Science 325:1531-1534.

Wada E, Way J, Lebacq-Verheyden AM, Battey JF (1990) Neuromedin B and gastrin-releasing peptide mRNAs are differentially distributed in the rat nervous system. J Neurosci 10:2917-2930.

Wang MW, Young AA, Rink TJ, Cooper GJ (1991) 8-37h-CGRP antagonizes actions of amylin on carbohydrate metabolism in vitro and in vivo. FEBS Lett 291:195-198.

Wiley RG, Lappi DA (2003) Targeted toxins in pain. Adv Drug Deliv Rev 55:1043-1054.

Wiley RG, Lemons LL, Kline RH 4th (2009) Neuropeptide Y receptorexpressing dorsal horn neurons: role in nocifensive reflex responses to heat and formalin. Neuroscience 161:139-147.
Xu XJ, Hökfelt T, Wiesenfeld-Hallin Z (2010) Galanin and spinal pain mechanisms: past, present, and future. EXS 102:39-50.

Zhang X, Xu ZQ, Bao L, Dagerlind A, Hökfelt T (1995) Complementary distribution of receptors for neurotensin and NPY in small neurons in rat lumbar DRGs and regulation of the receptors and peptides after peripheral axotomy. J Neurosci 15:2733-2747.

Zhang X, Shi T, Holmberg K, Landry M, Huang W, Xiao H, Ju G, Hökfelt $T$ (1997) Expression and regulation of the neuropeptide Y Y2 receptor in sensory and autonomic ganglia. Proc Natl Acad Sci U S A 94:729-734.

Zhang X, Xu ZO, Shi TJ, Landry M, Holmberg K, Ju G, Tong YG, Bao L, Cheng XP, Wiesenfeld-Hallin Z, Lozano A, Dostrovsky J, Hökfelt T (1998) Regulation of expression of galanin and galanin receptors in dorsal root ganglia and spinal cord after axotomy and inflammation. Ann N Y Acad Sci 863:402-413.

Zylka MJ, Rice FL, Anderson DJ (2005) Topographically distinct epidermal nociceptive circuits revealed by axonal tracers targeted to Mrgprd. Neuron $45: 17-25$. 